\title{
Pavlov's Reflex before Pavlov: Early Accounts from the English, French and German Classic Literature
}

\author{
Sven Jarius Brigitte Wildemann \\ Department of Neurology, University of Heidelberg, Heidelberg, Germany
}

\section{Keywords}

History of neurology · Cognitive neuroscience · Classical conditioning · Ivan Petrovich Pavlov (1849-1936)

\begin{abstract}
The concept of classical conditioning (CC), strongly connected with the name and work of the Russian physiologist Ivan Petrovich Pavlov (1849-1936), has become the foundation of the modern science of learning and, in particular, of the influential theories of Watson and Skinner and the entire school of behaviourism. In this paper, we give a number of forgotten accounts of CC in the English, French, and German classic literature that pre-date Pavlov's reports by decades or even centuries. These instances are taken from works of the $16 \mathrm{th}, 18 \mathrm{th}$, and 19th centuries - authored by some of the finest writers of England (Sterne, Locke), France (Rabelais), and Germany (Jean Paul) - and indicate that the psychological mechanisms now described as CC were known long before Pavlov and his successors elaborated on them in a systematic way.

(c) 2017 S. Karger AG, Basel
\end{abstract}

Ivan Petrovich Pavlov (1849-1936) played a seminal role in "[defining] classical conditioning" (CC) and "[identifying] other processes linked to it: generalization, discrimination and extinction" [1]. These concepts have become the foundation of the modern science of learning and, in particular, of the influential theories of Watson and Skinner and the entire school of behaviourism.

In brief, the term 'classical conditioning' is used to refer to a process of learning that is induced by the repeated pairing of a neutral stimulus with a potent biological stimulus (called the unconditional stimulus) eliciting a usually innate reaction (termed the unconditional reaction). This leads to the former neutral stimulus becoming a more or less potent, so-called conditional stimulus that is able to elicit the unconditional reaction.

While the concept of CC is strongly connected with Pavlov's name, he was neither the first nor the only researcher to work on that topic ${ }^{1}$. In Philadelphia, Edwin B. Twitmyer (1873-1943) had independently discovered CC

\footnotetext{
${ }^{1}$ This is not different from other areas of research. New theories as well as scientific discoveries rarely come from scratch. New generation scientists are usually seeing farther because they are standing - or sitting, as the windows of the Southern transept of Chartres suggest [Merton, On the Shoulders of Giants: A Shandean Postscript. Post-Italianate Edition, 1993] - on the shoulders of their predecessors (perhaps with the exception of the social sciences, in which each new generation steps into the face of their predecessors according to a bon mont by David Zeaman [cited after Merton 1993]), and most ground-breaking theories in the history of science have been adumbrated by observations made and ideas first enunciated by others.
}

\section{KARGER}

(C) 2017 S. Karger AG, Basel 
and published his results one year ${ }^{2}$ before Pavlov made his theories public. In Austria, the Vienna-based physiologist Alois Kreidl (1864-1928) had reported on his experiences with CC in fish almost a decade before Pavlov ${ }^{3}$ [2]. Finally, Vladimir Mikhailovich Bekhterev (1857-1927), well known to physicians as the eponym of a plethora of anatomic structures, clinical phenomena, signs and syndromes and diseases and to psychologists as the father of 'objective psychology' $[3,4]$, claimed that he and his coworkers had started to work experimentally on the concept of CC in the 1880s [5]. Kreidl even traced the origins of the idea back to 1835 and maintained that it had been present in the scientific literature throughout the 19th century [2].

It is also well known that Pavlov owed much to Ivan Mikhaylovich Sechenov's (1829-1905) materialistic views on reflexology, which he "transformed into a theoretical and general view on the conditional reflexes and even more generally on the functioning of the brain" [6], as well as to the concept of 'association' in general, which had re-entered philosophy in the 17th century with the writings of John Locke (1632-1704) and then remained a frequent topic in both philosophy and psychology.

It is therefore not totally astonishing that the phenomenon did not go unrecognized in the fine literature which at all times has produced the most meticulous observers of human psychology and behaviour.

\footnotetext{
${ }^{2}$ We refer to the first presentation outside of Russia on the occasion of the XIV. International Medical Congress in Madrid (1903). For the sake of exactness it should not go unmentioned that I. Tolotchinov, one of Pavlov's closest collaborators at that time, gave a talk on the physiology and psychology of the salivary glands (in the French language) already in July 1902 at a congress in Helsinki (then still under Russian rule) in which he presented data from Pavlov's laboratory and unveiled Pavlov's term "réflexe conditionnel" [Tolotschinoff, Contribution à l'étude de la physiologie et de la psychologie des glandes salivaires, 1903; Todes, Ivan Pavlov. A Russian Life in Science, 2014].

${ }^{3}$ It is remarkable from the point of view of epistemology and history of science how phenomena that are already known often get recognized by the scientific community only as soon as specific conditions are met, which are often extrinsic to the phenomenon itself - such as the person attending to them: While Pavlov's work was considered "revolutionary," the experiments of Twitmyer went largely unrecognized and Twitmyer himself is widely forgotten nowadays [Am J Psychol 1943;56:451-453]. Similarly, Kreidl's experiments did not generate large interest in the scientific community when published in 1896 [J Hist Behav Sci 2002;38:393-403]. Given that Pavlov was a rather well-established scientist at the time he made his findings on $\mathrm{CC}$ available to the scientific community, Twitmyer and Kreidl both seem to have fallen victim to what has been called the Matthew effect, and Kreidl's case may represent an example of Merton's palimpsestic syndrome [Merton, On the Shoulders of Giants: A Shandean Postscript. Post-Italianate Edition, 1993]: antecedent versions of an idea may fall into oblivion when new versions are presented (though it is undoubtedly true that Pavlov's experimental works and his elaborated theoretical system as well as the sheer output of his "physiological factory" [Todes, Pavlov's Physiology Factory: Experiment, Interpretation, Laboratory Enterprise, 2001] highly surpasses Twitmyer's and Kreidl's contribution, which ultimately justifies history's verdict).
}

Pavlov's Reflex before Pavlov
Here, we would like to point to some very early but so far widely overlooked accounts of CC in the French, German and English classic literature, which predate Pavlov's reports by decades or even centuries. All of those instances are taken from fictional works of the 16th, 18th, and 19th centuries - rather than from the scientific literature.

The earliest instance we present dates back to the first half of the 16th century and can be found in the works of one of the greatest French writers of that time, François Rabelais (between 1483 and 1494-1553) (Fig. 1). In chapter VII of his La Vie très horrifique du grand Gargantua, père de Pantagruel, in which we learn after what curious manner the protagonist received his name and how he, at just 22 months of age, learned to adore the stimulating effects of wine, we read:

Une de ses gouvernantes m'a dict [...] que de ce faire il estoit tant coustumier [i.e., to his daily ration of that juice de paradis or purée septembrale as Rabelais poetically names it], qu'au seul son des pinthes et flaccons il entroit en ecstase, comme s'il goustoit les joyes de paradis. En sorte qu'elles, considerans ceste complexion divine, pour le resjouir, au matin, faisoient davant luy sonner des verres avecques un cousteau, ou des flaccons avecques leur toupon, ou des pinthes avecques leur couvercle, auquel son il s'esguayoit, il tressailloit, et luy mesmes se bressoit en dodelinant de la teste, monichordisant des doigtz et barytonant du cul. (One of his governesses told me, [...] how he was so accustomed to this [i.e., wine], that, at the sound of pints and flagons, he would on a sudden fall into an ecstasy, as if he had then tasted of the joys of paradise. So that they, upon consideration of this, his divine disposition, would every morning, to cheer him up, play with a knife upon the glasses, on the bottles with their stopples, and on the pottle-pots with their lids and covers, at the sound whereof he became gay, did leap for joy, would loll and rock himself in the cradle, then nod with his head, monochordizing with his fingers and barytonizing with his stern [from Sir Thomas Urquhart of Cromarty's acclaimed classical translation of 1653].)

Here, wine is the unconditional stimulus and the child's digestive reactions, indicated by Rabelais in his typical ribald manner, alongside the neurophysiological correlates of euphoria caused by the consumption of wine, are the corresponding unconditional reaction. The clinking of the bottles is the repeatedly presented paired neutral stimulus that subsequently turns into a conditional stimulus. Similarly, the sound of the cork being withdrawn from a wine bottle becomes a secondary conditional stimulus. The careful observation that the sound of small kitchen pots, which is different from that of glass bottles, was capable of acting as a sufficient stimulus as well can be taken as an early example of what would later be called "stimulus generalization": after a given neutral stimulus has been converted into a conditional stimulus, similar stimuli will elicit the same conditional reaction. Of note, even an artificial stimulus

Eur Neurol 2017;77:322-326 

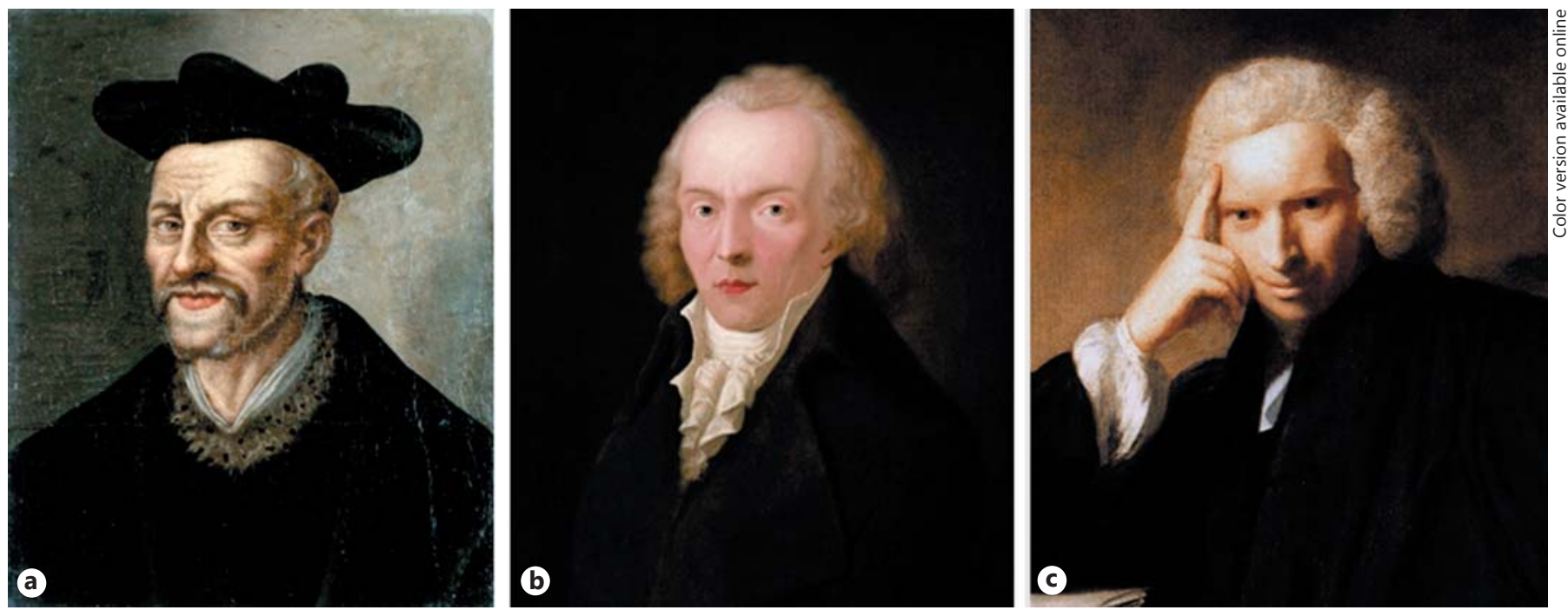

Fig. 1. Seventeenth- and 18th-century portraits of (a) François Rabelais (1483/1494-1553), (b) Jean Paul (1763-1825) and (c) Laurence Sterne (1713-1768). a Anonymous painter, 17th century, oil on canvas, Musée de Versailles, France; b Heinrich Pfenninger
(1749-1815), 1798, oil on canvas, for Gleim's (1719-1803) Temple of Friendship, Gleimhaus Halberstadt, Germany; c Sir Joshua Reynolds (1723-1792), 1760, oil on canvas, National Portrait Gallery, UK. mimicking the original stimulus, such as the sound of a knife hitting against a bottle in imitation of the clinking of wine bottles, is capable of evoking the conditional reaction in little (or in fact not so little) Gargantua. The pairing of auditory and alimentary stimuli as observed by Rabelais should become one of the major research interests of Pavlov and his co-workers more than 300 years later. It is little known but of interest in our context that the experiments on unconditional stimulus-induced digestive reactions performed in Pavlov's laboratory involved not only animals but also children. A rare depiction of these experiments, which would be considered unethical nowadays, is to be found in the 1926 Soviet educational film Mechanics of the Brain (original Russian title Механика головного мозга), directed by Vsevolod Illarionovich Pudovkin (1893-1953), a recently rediscovered early attempt to popularise Pavlov's studies in CC $[7,8]$.

The second example is taken from Jean Paul's (Johann Paul Friedrich Richter, 1763-1825) Selberlebensbeschreibung (1818-1819; published posthumously under the title Wahrheit aus Jean Pauls Leben), his unfinished autobiography covering the early years of his life ${ }^{4}$. Jean

\footnotetext{
${ }^{4}$ Not to be confused with his Konjektural-Biographie, a rare example of an autobiography that describes not the author's past life, but the story of his future (sic!) life.
}

Paul, once characterized by the "German Voltaire" Christoph Martin Wieland (1733-1813) as "our Yorick (i.e., the Germans' Sterne), our Rabelais" ", was one of Germany's most widely read poets in the early 19 th century. On pages 69-72 of the 1826 edition [9], we are informed about young Johann's (Jean Paul adopted his nom de plume only in 1793 in honour of Jean-Jacques Rousseau) first love. The object of his affection was Augustine, a young peasant girl. Jean Paul vividly describes the emotional response (unconditional reaction) evoked by the sight of the girl (unconditional stimulus), in particular by her physical attributes, the "thousand traits" of her physiognomy, which "like a magic circle capture[d] [his] heart." As their meetings only took place in the evenings, when Augustine herded her family's cows towards the farm, the unconditional stimulus, that is, the sight of the object of his affection, was always predicted by the sound of cowbells (the neutral stimulus). This repeatedly presented paired stimulus established a conditioned reflex that was so stable that the same physical and emotional reactions originally caused by seeing her, namely, in physiological terms, tachycardia and increased blood pressure, endorphin release, and lacrimation (or, in

\footnotetext{
${ }^{5}$ A sobriquet given to Wieland by no less a figure than Napoleon Bonaparte. ${ }^{6}$ Cited from a letter by Charlotte von Kalb (1761-1843) to Jean Paul, dated February 29, 1796 [Herrlich, Briefe von Charlotte von Kalb an Jan Paul und dessen Gattin, 1882].
} 
the poet's more romantic words, "poppling and bubbling of my heart's blood," happiness and tears of joy) were inducible by the sound of cowbells still many years after their last encounter.

The third potential instance is an episode from Laurence Sterne's (1713-1768) The Life and Opinions of Tristram Shandy, Gentleman, described in the fourth chapter of the first volume (published in 1759) of that "greatest of all novels" (Schopenhauer). As the reader will know, Sterne was highly familiar with the works of Rabelais, whom he considered a paragon of humorous writing and from whom he extensively quoted. This passage is so well-known that we prefer to "shut the door" and not to cite it in length. If we assume, as the superb 2005 film adaptation of the novel [10] by the British director Michael Winterbottom suggests, that the sound of winding up the clock (as the conditional stimulus), elicited not only an "idea," Sterne here clearly describes the concept of CC. Of note, the stimulus meets all criteria for an effective neutral stimulus: As Sterne himself emphasizes, it had originally "no connection in nature" with the response; it was repeatedly co-presented (the clock has been wound up monthly for many years); and it always preceded - and thus predicted - the unconditional reaction. Sterne even recognized that the newly established connection between the neutral stimulus and the unconditional reaction was an involuntary or automatic one (a 'reflex'): the conditional stimulus caused the conditional reaction "unavoidably"; the latter "popped into her head". This 'mechanistic' aspect is paralleled by Sterne's reference to a clockwork, at that time a frequent metaphor in materialist discussions for the way the human mind and body work (La Mettrie's Le Homme machine had appeared in 1749).

Using a Lockeian term, Sterne referred to the phenomenon as a "strange combination" or "unhappy association" of ideas. Pavlov would later speak about an "elaboration of a temporary conditioned connexion, an association" [11], and Bekhterev would use the term "association reflex" to refer to CC. John Locke (1632-1704), in his Treatise upon understanding (1690), a copy of which Pavlov had acquired in 1898 [12], had described "[i]deas that in themselves are not all of kin" but nevertheless "come to be so united in some men's minds, that it is very hard to separate them" once settled, and speculated that those connections are "made by custom". Custom or habit, that is, repetition, causes "trains of motions in the animal spirits" that "once set a-going, continue in the same steps they have used to, which, by often treading [our emphasis], are

Pavlov's Reflex before Pavlov worn into a smooth path, and the motion in it becomes easy, and as it were natural" (an idea that adumbrates long-term potentiation $)^{7}$. Two events "not allied by nature" (e.g., "darkness" and the feeling of fear upon hearing stories about "goblins and spirits") become inseparable if they are being "raised together" and "inculcated" in someone's mind "over and over". The mind "confounds" the two stimuli, resulting in both causing the same reaction. Only if the 2 stimuli are no longer presented together might time extinguish their connection in a person's mind. It is therefore not entirely without justification when Michael Winterbottom in his A Cock and Bull Story calls Pavlov's concept a "19th century update" on Locke's "association of ideas" [10].

We are well aware of the dangers of adumbrationism [13] and do not want to overstate the case, all the more as it is unknown if Pavlov besides Locke's essay ever read any of the literary works mentioned above ${ }^{8}$, but we believe that the resemblance of these accounts with CC is so striking that it is worthwhile pointing to them. Given that CC entered scientific psychology only with Pavlov, i.e., at the beginning of the 20th century, these instances confirm the epistemic insight that "[often] an event or observation that is commonly known is not "known to science" " [2].

Of note, in all three examples cited above, the neutral stimulus was an auditory stimulus: a clock being wound up, the clinking of bottles, and the peal of cowbells. This

7 Cf. Sterne's famous words on the strong influence of the animal spirits: "Well, you may take my word, that nine parts in ten of a man's sense or his nonsense, his successes and miscarriages in this world depend upon their motions and activity, and the different tracks and trains you put them into, so that when they are once set a-going, whether right or wrong, 'tis not a halfpenny matter, - away they go cluttering like hey-go mad; and by treading the same steps over and over again, they presently make a road of it, as plain and as smooth as a garden-walk, which, when they are once used to, the Devil himself sometimes shall not be able to drive them off it." (Tristram Shandy, Book I, chapter I, p. 1).

8 Pavlov was certainly a polymath interested in science, art and literature. According to E.A.Kosmachevskaia, L.I. Gromova and A.N.Borgest [Библиотека Ивана Петровича Павлова, 2001], Pavlov's private library in St Petersburg contained, besides a vast collection of scientific books and papers, an extra bookshelf with 600 books of his favourite writers and poets. Whether that collection included Rabelais' and Sterne's works is unknown to us. Sterne had Russian followers from the very beginning - the most illustrious being Czarina Catherine II (1729-1796), an ardent admirer of that author [Stewart, From Imperial Court to Peasant's Cot: Sterne in Russia, 2004], and translations have been available since 1779. The first, though fragmentary, Russian translations of Rabelais date back to the 18th century, too; however, considered 'untranslatable' for a long time, Rabelais seems to have entered Russian culture much later [Bakhtin, Rabelais and His World, 1968]; Lyubimov's acclaimed translation appeared in 1961. It is worthwhile noting in this context that Pavlov had sufficient command of both the French and the German language (as many readers will know, Pavlov gave his Nobel Laurate speech in 1904 in German) [Todes, Ivan Pavlov. A Russian Life in Science, 2014]. 
directly reminds one of the iconic 'dog-and-bell scenario' usually associated with Pavlov's CC experiments. While there is some doubt whether Pavlov ever used a conventional handbell (let alone a cowbell) as conditional stimulus $[1,14,15]$, there is sufficient evidence for the frequent use of auditory conditional stimuli (electric bells, metronomes, impure tones such as the sound of air bubbling through water) in Pavlov's laboratory as recently summarized by us and others $[16,17]$.

We are positive that further early instances of classic conditioning can be found in the literature. However, the accounts given above are sufficient to indicate that the psychological mechanisms now described as CC were known long before Pavlov and his successors elaborated on them in a systematic way - although they had never before been made the object of experimental research, which will remain the lasting merit of Pavlov.

\section{Disclosure Statement}

The authors declare that they have no conflicts of interest.

\section{References}

1 Cambiaghi M, Sacchetti B: Ivan Petrovich Pavlov (1849-1936). J Neurol 2015;262:1599_ 1600.

$>2$ Logan CA: When scientific knowledge becomes scientific discovery: the disappearance of classical conditioning before Pavlov. J Hist Behav Sci 2002;38:393-403.

3 Lerner V, Margolin J, Witztum E: Vladimir Mikhailovich Bekhterev (1857-1927). J Neurol 2006;253:1518-1519.

4 Akimenko MA: Vladimir Mikhailovich Bekhterev. J Hist Neurosci 2007;16:100-109.

5 Todes DP: Ivan Pavlov. A Russian Life in Science. Oxford, Oxford University Press, 2014.

6 Buser P: Slowly forgetting the Pavlovian adventure? C R Biol 2006;329:398-405.
7 Pudovkin V (ed): Mechanics of the Brain (original Russian version), Moscow 1926. http://www.youtube.com/watch?v=YTc06C fIJY (accessed April 27, 2016).

8 Pudovkin V (ed): Mechanics of the Brain (1960 version with English captures), Moscow 1926/1960. https://vimeo.com/20583313 (accessed April 27, 2016).

9 Paul J: Heftlein 1. Breslau: Josef Max und Komp, 1826.

10 Winterbottom M, Coogan S, Hardy M, Eaton A, Brydon R, Hawes K, et al (eds): A Cock and Bull Story, Lions Gate Home Entertainment UK, 2005.

11 Pavlov IP: An attempt to understand the symptoms of hysteria physiologically; in Gantt WH (ed): Lectures on Conditioned Reflexes. New York, International Publisher Co. Inc., 1941, pp 102-116.
12 Kosmachevskaia EA, Gromova LI, Borgest AN: Библиотека Ивана Петровича Павлова. Ross Fiziol Zh Im I M Sechenova 2001;87:428-438.

13 Merton RK: On the Shoulders of Giants: A Shandean Postscript. Post-Italianate Edition. Chicago and London: University of Chicago Press, 1993.

14 Catania AC: Query: Did Pavlov's Research Ring a Bell? Psycholoquy Newsletter, Tuesday June 7, 1994.

15 Littman RA: Bekhterev and Watson Rang Pavlov's Bell. Psycoloquy 1994;5:1.

16 Tully T: Reply: the myth of a myth. Curr Biol 2003;13:R426.

17 Jarius S, Wildemann B: And Pavlov still rings a bell: summarising the evidence for the use of a bell in Pavlov's iconic experiments on classical conditioning. J Neurol 2015;262:2177-2178. 